\title{
Omphalocele with ectopic liver forming a mesodermal cyst
}

\author{
Horn $\mathrm{F}^{1}$, Kubikova $\mathrm{E}^{2}$, Dubravova $\mathrm{D}^{1}$, Babal $\mathrm{P}^{3}$, El Falougy $\mathrm{H}^{2}$, Selmeciova $\mathrm{P}^{2}$, Hajnovic $\mathrm{L}^{4}$ \\ Department of Pediatric Surgery, Faculty of Medicine, Comenius University in Bratislava, Slovakia. \\ eliska.kubikova@fmed.uniba.sk
}

\begin{abstract}
Background: Congenital anomalies of the abdominal wall are classified as anomalies with the abdominal wall defect (omphalocele, gastroschisis) and without the defect (umbilical hernia, persistent ductus omphaloentericus or urachus). Clinical presentations of these conditions are different, and so is the timing of surgical intervention and approach with or without the exploration of the peritoneal cavity.

Case: The presented case report refers to a rare finding of ectopic liver forming mesodermal cyst within the umbilical region. Full term neonate girl with $5 \mathrm{~cm}$ spheroid tumor in umbilicus was otherwise without problems. Ultrasonography (USG) of the lesion detected a tissue with good vascularization and a cystic cavity. There was no flow in the umbilical vessels and no evidence of intestinal loop in the sac. USG of the liver was normal. During surgery an additional narrow canaliculus was identified connecting the spheroid along with umbilical vessels to the liver. The whole spheroid together with the canaliculus was surgically removed without exploration of the abdominal cavity. Histological evaluation of the surgical specimen discovered liver tissue with a mesodermal cyst in the center. The sphere was connected to the liver by a bile duct. Six months after the operation the child is in a good clinical condition.

Conclusion: In conclusion omphalocele may contain liver. Ectopic liver is an extremely rare condition. Surgical treatment in the presented case focused only on umbilicus without exploration of the abdominal cavity and appeared to be sufficient. Long-term postoperative follow up typical in pediatrics will be applied also in this patient (Fig. 3, Ref. 25). Full Text in PDF www.elis.sk.

Key words: omphalocele, ectopic liver, mesodermal cyst, hernia, umbilicus.
\end{abstract}

Congenital abdominal wall (AW) anomalies are classified into two categories, with or without the AW defect (1). Gastroschisis and omphalocele are the most common abnormalities with the defect of AW (2). This group includes anomalies with low incidence e.g. medial and vesicointestinal fissure. The common factors are serious clinical manifestations and acute need of surgical management immediately after birth. Umbilical and supraumbilical hernia, persistent omphaloenteric duct, persistent urachal fistula and diastasis of the rectus abdominis muscles belong to the group of congenital anomalies without AW defect. Their manifestations and consequences at uncomplicated course range them to minor anomalies and their surgical treatment is in most cases elective (3).

${ }^{1}$ Department of Pediatric Surgery, Faculty of Medicine, Comenius University in Bratislava, Slovakia, ${ }^{2}$ Department of Anatomy, Faculty of Medicine, Comenius University in Bratislava, Slovakia, ${ }^{3}$ Department of Pathological Anatomy, Faculty of Medicine, Comenius University in Bratislava, Slovakia, and ${ }^{4}$ Klinik für Thorax- und Gefäßchirurgie, Klinikum Chemnitz, Germany

Address for correspondence: E. Kubikova, MD, PhD, Institute of Anatomy, Faculty of Medicine, Comenius University, SK-813 72 Bratislava, Slovakia. Phone: +421.2 .59357390$

Acknowledgement: The presented work was supported by the Framework Programme for Research and Technology Development, project: Building of Centre of Excellency for Sudden Cerebral Vascular Events, Comenius University Faculty of Medicine in Bratislava (ITMS: 26240120023), co financed by European Regional Development Fund. Our thanks belong to Mrs. E. Klincova for excellent lab work.
The presented report shows that there are cases in which the exact clinical classification is difficult. Sometimes only the microscopic analysis allows identifying the type of anomaly more accurate. We report a unique and rare abnormality, an ectopic mesodermal liver cyst of the umbilical cord. The aim of our case presentation is to draw medical society's attention to this possible pathological-anatomical variation and the surgical treatment of this condition

\section{Case Report}

A girl born by normal spontaneous delivery without complications at 39th week of gestation with a good postnatal adaptation had an asymptomatic spheroid of $4 \mathrm{~cm}$ in diameter in the umbilicus. On the 6th day after birth she was transferred to the Department of Pediatric Surgery. The spheroid diameter was increased and measured $5 \mathrm{~cm}$, with wide skin stalk and a membrane covering a violet - brown elastic tissue shining through it. Ultrasonography of the liver and the biliary tract showed no associated pathology. The spherical body was not associated to an intestinal loop; it was composed of $17 \mathrm{~mm}$ thick tissue with good vascular supply and a cyst of $18 \mathrm{~mm}$ in diameter with fluid collection. Umbilical veins were without flow.

At surgery, we found standard structures of the umbilicus with redundant accessory vascularization and a thin canaliculus along with the vessels of the umbilical cord connected to the liver. The structures were resected via ligatures together with 

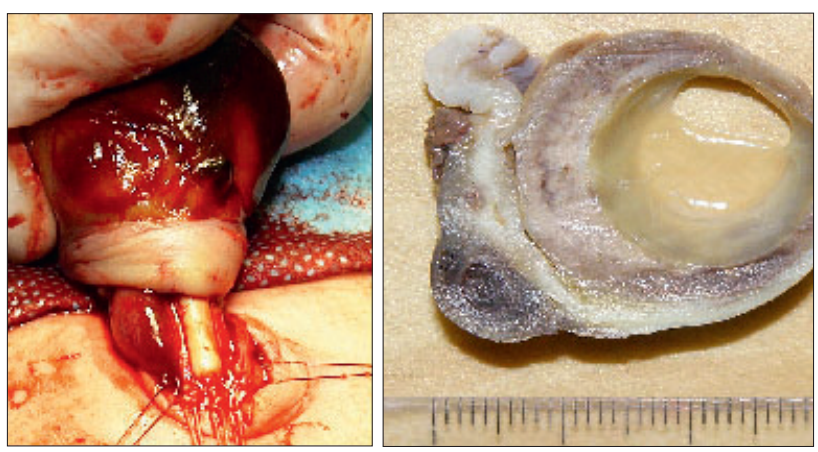

Fig. 1. Per operative view and section. Sliced through surgical specimen of the umbilical spheroid with a central cavity filed with gelatinous material; on the left side are remnants of the offset of the umbilicus with umbilical vessels.
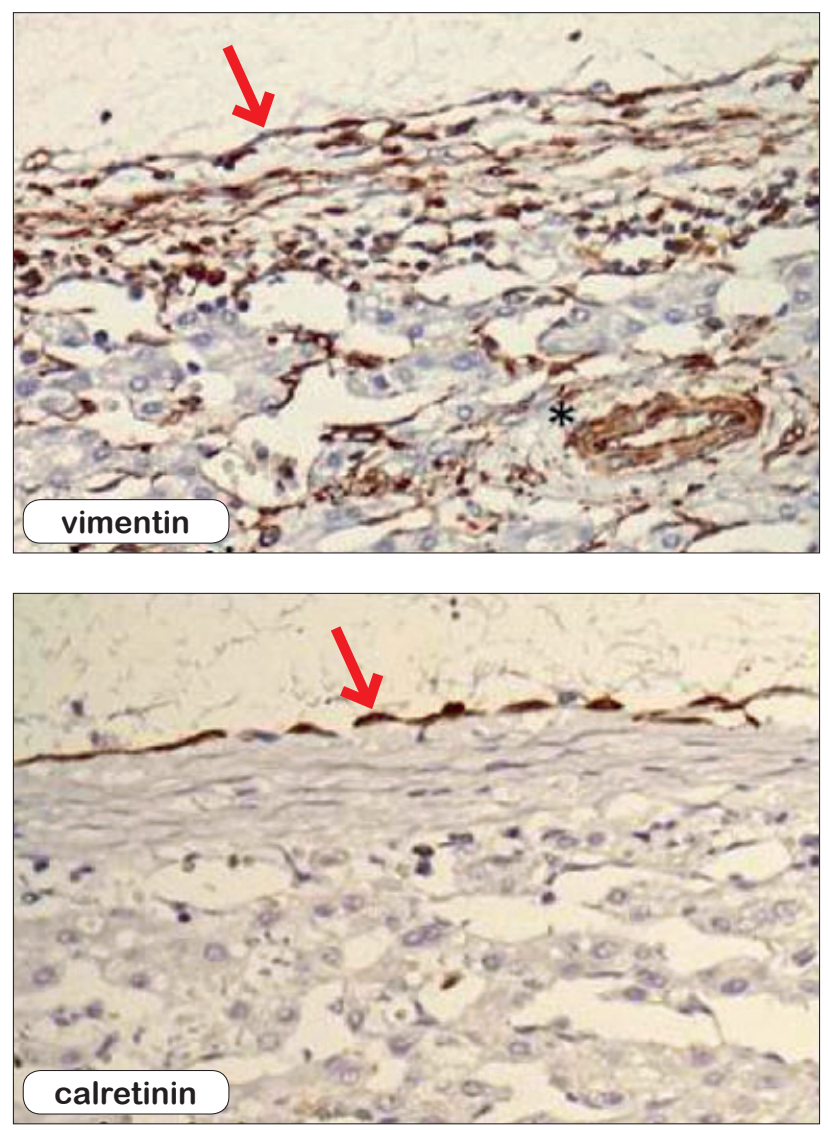

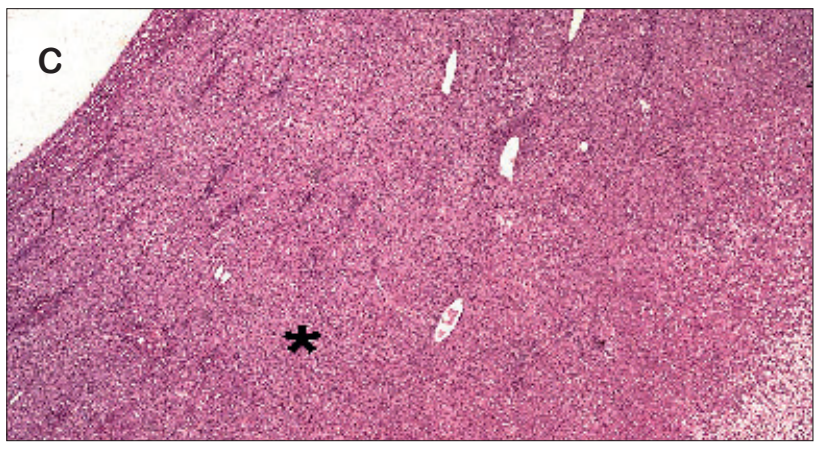

Fig. 2. Histological section of the umbilical spheroid consisting of mature liver tissue (*) forming a wall around central cavity (C) lined by flat epithelium-like cells. Hematoxylin \& eosin (HE), x25.
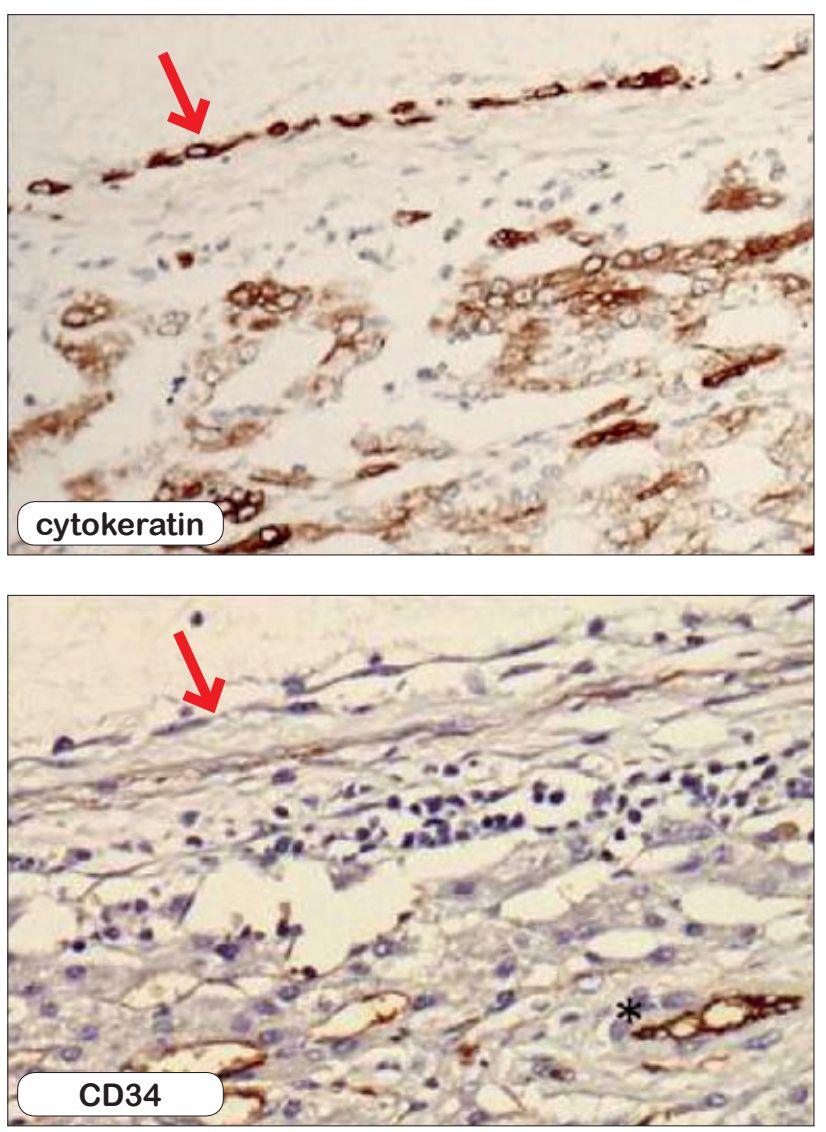

Fig. 3. Immunohistochemical analysis proved the mesothelial character of the cystic cavity pavement (arrow) showing positive reactivity for cytokeratins, calretinin and vimentin and negative staining for CD34 endothelial marker. Streptavidin-biotin-peroxidase complex, diaminobenzidine, counterstained with hematoxylin, $\mathbf{x} 200$.

the spheroid (Fig. 1). No immediate postoperative complications were detected and the patient was dismissed from hospital. The material from the umbilicus was sent for histological examination, which identified a cystic cavity lined with flat cells and thick wall formed by well structured liver tissue (Fig. 2). The lining of the cyst was immunohistochemically CD 34 negative (endothelium), calretinin positive (mesothel), AE1 weakly positive (cyto- keratins) and vimentin positive (mesenchyma), corresponding to a mesothelial lining (Fig. 3).

The liver tissue was connected to the liver by a bile duct without structures of ductus omphaloentericus. Three months after the first surgical intervention a revision of the operation wound was performed for persisting local inflammation and secernation with the peroperative finding of granulation tissue around the sutures. After 
the second intervention, the wound has healed and the patient is without any clinical complications. Histology on the second intervention confirmed a giant cell granulomatous reaction around the sutures.

\section{Discussion}

Umbilical cord develops in the 4th week of embryogenesis. It is composed of one umbilical vein, 2 umbilical arteries, omphaloenteric duct, urachus and myxomatous tissue Wharton's jelly. The omphaloenteric duct and urachus obliterate prenatally. Umbilical vessels constrict and obstruct perinatally with the closure of the placental circulation (4). The most common and also the least severe congenital anomaly of the umbilical cord is the umbilical hernia. It has the same characteristics as other hernias: neck, sac and content. The neck of the umbilical hernia remains open due to the persisting cord of the umbilical vessels or due to the immaturity of the child. The sac is formed by peritoneum and the skin. The content, in addition to the already mentioned umbilical cord residues, is usually omentum or bowel, which protrudes through the abdominal wall only with the increased intra-abdominal pressure. In most cases umbilical hernia resolves spontaneously, a smaller percentage of patients are indicated for surgical treatment after the second year of life.

Omphalocele is a congenital defect of the abdominal wall due to perturbance of the mesenchyma evolution in the umbilical area (4). Failure of the first phase of intestinal rotation participates at the development of omphalocele (5). Return of the physiological embryonic hernia is incomplete and the intestinal loop remains in the umbilical coelom. Postnatally, patients have intestinal malrotation, short bowel and complications due to ischemia or stagnation of the intraluminal content (6). Frequently the sac of the omphalocele contains liver, the whole organ or a part thereof. Omphalocele is a defect diagnosable by prenatal ulrasonography. Patients with omphalocele tend to have other, sometimes quite uncommon associated anomalies $(7,8)$. One-step closure operation is the optimal method of surgical treatment. In the second place is a multi-step surgery or various methods of bandaging and treatment, in order to return the organs to the abdominal cavity and reduce the sac $(1,9,10,11,12)$.

Liver develops in the $3 \mathrm{rd}$ week of gestation as a ventral bud of the foregut's endoderm at the point of future basis of duodenum. From this hepatic bud (pars hepatica) arises a secondary bud (pars cystica) as the base of gallbladder and bile ducts. The endoderm of pars hepatica proliferates rapidly and in the form of cell trabecules it grows into the sheets of ventral mesentery on the left and right side of duodenum and so it forms left and right lobe of the liver. By growing of the liver trabecules into the mesenchyme of septum transversum, where the sinus venosus passes, the trabecules contact and brake up venae omphalomesentericae in order to form primitive liver sinusoids. With luminisation and flattening of liver trabecules in pars hepatica evolve the intrahepatal bile ducts and ductus hepaticus, with luminisation of pars cystica develop the gallbladder and ductus cysticus (4).

The liver ectopia is a rare anomaly when compared with the appearance of ectopia in various other sites as gallbladder, liga- mentum hepatogastricum, omentum, umbilicus, pylorus, spleen, adrenals, retroperitoneum $(13,14)$. The ectopic liver probably develops due to the regression and atrophy of the original connections between hepatocyte trabecules and native liver (ectopia in the gallbladder, ligamentum hepatogastricum) $(14,15,16)$ or due to trapping the hepatocytes by adjacent mesenchyma while forming the liver sinusoids (from the cells of pars hepatica) and their subsequent migration to more distant areas (retroperitoneum, umbilicus, etc.) (17). In the case of dorsal budding of the liver tissue before closure of the pleuroperitoneal canal, ectopic liver may occur in the thoracic cavity (oesophagus, pericardium, pleura) $(18,19)$. Diagnosis and treatment of liver ectopia depends on clinical symptoms. In most cases, the discovery of ectopic liver may be a surprising finding during a common surgical procedure in the results obtained from histological examination; anyway it may incidentally give rise to malignant tumors in adults. As to its prognosis in infancy, there is no evidence-based data of accidentally found ectopic liver-tissue yet.

Ductus omphaloentericus persistens (DOP), urachus patens, cysts and pseudocysts of the umbilicus are other congenital anomalies that occur in the area of umbilicus (20). Not closed DOP presents by secernation from the navel and its diagnosis is not easy. Ultrasonographic examination is a method of choice and sometimes it is sufficient. To display the communication with the gastrointestinal tract the X-ray contrast examination may be used. Closed but persistent band of DOP could be the cause of ileus in a child (21). The therapy of DOP is only surgical and the extent of laparoscopy or laparotomy depends on the patient's condition, symptoms and complications (22). Meckel's diverticulum is the remnant of DOP. Sometimes it can be the content of hernia (Littre), it can get inflamed or it presents by enterorrhagia or ileus $(12,19,23,24,25)$. Therapy is surgical, laparoscopic or classical.

Urachus, cysts and pseudocysts usually manifest with secernation or presence of a formation in the umbilicus. Their course is usually complicated by infection. Surgical intervention is limited to the umbilical area.

The presented patient had a congenital anomaly, a spheroid in umbilicus diagnosed only after birth. It did not cause her any difficulties. During the first week the spheroid enlarged to $1 \mathrm{~cm}$ in diameter. Preoperative ultrasonography showed liver and bile ducts without pathological finding. Before surgery we presumed a communication with the intestine, however it was not confirmed. Surprising finding was the canaliculus that bound the spheroid together with the umbilical cord to the liver. In regard to this condition, we did not explore the abdominal cavity. We excised the spheroid completely and waited for the results of the microscopic analysis. The parenchyma of the spheroid in umbilicus was supplied by aberrant blood vessels from the surrounding area. Complications that occurred in the wound and necessitated a second intervention were the consequence of supernumerary vascular hemostasis through the sutures. At the second operation they were removed and there was no additional abnormality in the navel.

Fock (1963) described two newborns with omphalocelle (13). In both an ectopic lobe was completely detached from the liver itself and located outside the abdominal cavity. In the first case 
the hepatic lobe had apparently become detached at an early embryological stage, since the histological picture of the liver was extremely primitive. In the second case the hepatic lobe was perhaps detached in a late intrauterine stage, as its histological picture was characteristic of the mature liver, as in our case.

\section{Conclusion}

Congenital developmental anomalies of the umbilicus belong to a category of anterior abdominal wall defects. The spectrum of malformations is diverse. The issue is the exact classification and extent of surgical intervention. The presented case report refers to a very rare finding. We classify it as an omphalocele with ectopic liver forming a mesodermal cyst. Surgical treatment in our case focused only on umbilicus without the exploration of the abdominal cavity and appeared to be sufficient. Long term postoperative follow-up typical in pediatrics will apply also in the case of our patient.

\section{References}

1. Trnka J. Vrodené defekty brušnej steny. Bratislava; Bau press, 2008: $12-75$.

2. Trnka J, Cingel V, Horn F, Babala J, Sykora L, Beder I. Perinatal traumatism with gastroschisis. Bratisl Lek Listy 2007; 108 (12): 526-528.

3. Snyder CL. Current management of umbilical abnormalities and related anomalies. Semin Pediatr Surg 2007; 16 (1): 41-49.

4. Klika E. Embryologie. Prague; Avicenum, 1986: 24-56, 178-182.

5. Triantafyllidis I, Papapavlou L, Nikoloudis N, Economou A, Andreadis E, Chrissidou M, Georgakis K, Chrissidis T. Ectopic Liver Tissue Attached to the Gallbladder Wall: a case report. Cases J 2009; 2: 67-86.

6. Thambidorai CR, Arief H, Noor Afidah MS. Ileal perforation in segmental intestinal dilatation associated with omphalocoele. Singapore Med J 2009; 50 (12): e412-414.

7. Herman TE, Siegel MJ. Apert syndrome with omphalocele. J Perinatol 2010; 30 (10): 695-697.

8. Shakya VC, Agrawal CS, Shrestha NR, Dhungel K, Adhikary S. Omphalocele with dextrotardia-A rare association. JNMA J Nepal Med Assoc 2009; 48 (175): 249-251.

9. Almond S, Reyna R, Barganski N, Emran MA. Nonoperative management of a giant omphalocele using a silver impregnated hydrofiber dressing: a case report. J Pediatr Surg 2010; 45 (7):1546-1549.
10. Baird R, Gholoum S, Laberge JM, Puligandla P. Management of a giant omphalocele with an external skin closure system. J Pediatr Surg 2010; 45 (7): E17-20.

11. Kumar HR, Jester AL, Ladd AP. Impact of omphalocele size on associated conditions. J Pediatr Surg 2008; 43 (12): 2216-2219.

12. Šnajdauf J, Škába R. Detská chirurgie. Prague; Galén, Karolinum, 2005: 262-265.

13. Fock G. Ectopic liver in omphalocele. Acta Paediat 1963; 52: 288-292.

14. Leone N, Saettone $S$, De Paolis $P$, Carucci $P$, Brunello F, De Angelis C, Menozzi G, Rizzetto M. Ectopic livers and related pathology: report of three cases of benign lesions. Dig Dis Sci 2005; 50 (10): 1818-1822.

15. Kakitsubata Y, Kakitsubata S, Watanabe K. Hypoplasia of the right hepatic lobe with ectopy of the gallbladder. Clin Imaging 1995; 19 (2): $85-87$.

16. Hamdani SD, Baron RL. Ectopic liver simulating a mass in the gallbladder wall: imaging findings. AJR Am J Roentgenol 1994; 162( 3): 647-648.

17. Cardona D, Grobmyer S, Crawford JM, Liu C. Hepatocellular carcinoma arising from ectopic liver tissue in the pancreas. Virchows Arch 2007; 450 (2): 225-229.

18. Pampari D, Lacerenza C. Intrathoracic ectopy of an accessory lobe of the liver. Archivio Chir Torac 1961; 18: 557-565.

19. Avery G, Fletcher M, MacDonald M. Neonatology: pathophysiology and management of the newborn.4th ed. Philadelphia; Lippincott-Raven, 1994: 943-945.

20. Pal K, Ashri H, Al Wabari A. Congenital hernia of the cord. Indian J Pediat 2009; 76 (3): 319-321.

21. Babala J, Horn F, Cingel V, Trnka J. Occlusive ileus caused by intestinal duplication. Rozhl Chir 2007; 86 (9): 471-474.

22. Omaník P, Cingel V, Babala J, Béder I. Laparoscopy in the management of invagination in pediatric patiens. Rozhl Chir 2010; 89 (7): 406-410.

23. Horn F, Trnka J, Simicková M, Duchaj B, Makaiová I. Symptomatic Meckel's diverticulum in children. Rozhl Chir 2007; 86 (9): 480-482.

24. Komlatse AN, Komla G, Komla A, Azanledji BM, Abossisso SK, Hubert T. Meckel's diverticulum strangulated in an umbilical hernia. Afr J Paediatr Surg 2009; 6 (2): 118-119.

25. Skandalakis PN, Zoras O, Skandalakis JE, Mirilas P. Littre hernia: surgical anatomy, embryology, and technique of repair. Am Surg 2006; 72 (3): 238-243.

Received December 12, 2011. Accepted December 10, 2012. 